association must be representative of the trade or industry as a whole, or comprise such a majority of the trade that firms who are not members are too insignificant to affect the returns.

Such statistical research could take two main forms: that of the descriptive study as seen in the survey of milk consumption in England and Waies undertaken by the Milk Board: or of the investigation type as in the survey of nutrition effects of milk also undertaken by the Milk Board; or the investigation into the causes of the marked fluctuations in retail trade about Easter and Whitsuntide undertaken by the retail distributors' associations. Mr. Brown pleaded for greater participation in such research by the universities and for greater readiness to place statistical information at the disposal of the com. munity for the advancement of knowledge. $\mathrm{He}$ referred to examples of co-operation in this respect between the Retail Distributors' Association, the Bank of England and the London School of Economics, which while securing a check on possibilities of error and safeguarding the disclosure of individual sources of information, has made the collective returns accessible for research or public purposes.

At the final session on Sunday evening, Mr. Max Nicholson, secretary of Political and Economic Planning (PEP), gave an interesting account of how material for the PEP Press Report was compiled, which is of some interest to scientific workers as an example of the possibilities of the group method of inquiry and research into subjects in which very little published information is available, and especially in making available neglected experience and buried sources of information. Mr. Nicholson also stressed the value of PEP anonymity.

\title{
Society of Chemical Industry
}

\section{Autumn Meeting}

$\mathrm{T}$ HE autumn meeting of the Society of Chemical Industry held in Glasgow on September 16-20 was notable for a symposium of papers on the trend of progress. The opening paper, presented for the Food Group by Dr. L. H. Lampitt, referred to the part played by chemists in the effort of nations to secure self-sufficiency, and particularly to the issues involved in the storage and preservation of food. Dr. Lampitt asserted that although internationalism in the scientific world is less pronounced, we are heading towards international agreement in certain aspects of dietetics as well as towards increased Government control of the efforts of chemists in the field of food science.

On behalf of the Road and Buildings Materials Group two papers were presented. In the first of these, Mr. R. Fitzmaurice discussed the question how far standardization and how far freedom of design are to predominate in the building industry. Referring to the accumulation of the scientific knowledge necessary to replace tradition, Mr. Fitzmaurice indicated some of the possibilities which standardiza. tion offers, given close co-operation between the architect and engineer as in the "Mapin" system of instruction. $\mathrm{He}$ referred also to the question of building regulations and the obstacles they sometimes present to progress whether in the introduction of new materials or new methods. Mr. Fitzmaurice referred also to the large number of British standard specifications now in existence for building materials. Many of these should provide a valuable safeguard for the purchaser in respect of particular properties of materials which constitute a source of difficulty in practice, but many architects appear to be unaware of their existence. This position, however, may slowly change through the use of these specifications in official specifications for Government or local authorities works.

The second paper, by Mr. J. O. Willis, dealing with road design, urged a trunk road policy in the construction of which full advantage could be taken of modern practice of alignment, and all interruption of the main streams of traffic obviated by overbridges and properly laid-out junctions. $\mathrm{He}$ stressed the importance of standards of riding quality and the improvement of surface quality, particularly of the need for the introduction of new methods of laying bituminous roads. Resistance to skidding is of vital importance, and Mr. Willis considers that asphalt surfacings, finished with precoated chippings, are only a palliative. The ideal he suggested is a fine textured bituminous carpet impervious to water and presenting a uniform texture throughout its life. In the light of work in Great Britain and in Holland, rubber might play an important part in solving the problem.

The paper presented by Dr. V. E. Yarsley on behalf of the Plastics Group referred to the fact that, in the plastics industry, only rarely has one material dominated another. This position is likely to continue, although with the balance of power inclining in favour of the thermoplastics group. The current trend is towards improved tensile properties and greater stability to heat, making possible the use of higher temperatures and the production of larger moulded units. In the field of cellulose plastics, the development of quick-growing celluloses which can be produced within Great Britain or the Empire is an obvious gain in a national emergency. Cellulose triacetate is now a commercial possibility, and ethyl-cellulose is promising for coating and impreg. nating compositions. The attention now being devoted to the production of shock-resisting phenolic plastics should ultimately provide an entirely new field for exploitation, while extended phenols should also do much to emphasize the possibilities of plastics as "the fourth material of construction". Aminoplastics are also promising for transparent plastics, and other possibilities lie in laminated plastics and for creaseless fabrics. The increased use of plastics for the production of high-duty wheels, gears and bearings, and also for airscrews, struts and construction parts in aircraft is only one of the developments to be expected.

In the final paper of the symposium, Prof. W. M. Cumming and Mr. F. Rumford reviewed tendencies in chemical engineering both in regard to materials 
and to unit operations. In regard to the former they referred to the development of new alloys but stressed the importance of scientific comparison and selection. They referred also to the use of special steels for high-temperature and high-pressure reactions in view of the importance of creep at elevated temperatures as well as to the efforts being made to replace nickel at least in part by other metals in a number of special cast irons, and to the attention devoted to the technique of welding and the interest in organic materials such as rubber. Similarly, the authors briefly reviewed developments in heat transfer, filtration, size reduction, distillation, including the use of a true counter-current system throughout the column, evaporation, drying, dust removal and other unit operations, while in conclusion the question of education was discussed and the importance of avoiding uniformity of training was stressed.

Appropriately enough, a paper by Dr. R. Gilmour at a joint meeting with the Institution of Chemical Engineers on "Chemical Engineering in the Fermentation and Distilling Industries" had much to say about the place of art and science in the distillation of whisky, including the effect of air, water, malt and peat on the production of a high-class whisky.

\section{Diffraction and Refraction of Radio Waves}

$\mathrm{T}$ $\mathrm{HE}$ increasing application to various radio purposes of ultra-short electric waves of less than $10 \mathrm{~m}$. in wave-length has given a new stimulus to the problem of calculating the field strength at distances from the transmitter such that the jonosphere is of negligible influence. The solution of the problem of the diffraction of electric waves around the earth was first given on a sound basis by G. N. Watson in 1918, but this analysis involved assumptions which, while perfectly valid for the long and medium waves then in use for radio communication, are not justifiable for the ultra-short waves now being considered. For example, at long wavelengths, the conductivity of the earth may be assumed to be infinitely great for analytical purposes, but as the wave-length is reduced through and below $10 \mathrm{~m}$., the actual value of the conductivity and also the dielectric constant of the soil over which the waves are propagated has an important influence on the field strength at a distance from the souree. Furthermore, the height of the receiver above the earth's surface may no longer be assumed to be a negligibly small fraction of a wave-length, when the latter is only a metre or two.

In a recent paper published by T. I. Eckersley and G. Millington (Phil. Trans. Roy. Soc., A, 237, $273-309$; 1938), a phase-integral method has been applied to the problem of obtaining a formula for calculating the electric field at a distance from a wireless transmitter. This method agrees with Watson's theory in the case already considered by him, but it has the advantage that it more readily permits of extension to the case of finite earth conductivity and of an elevated transmitter and receiver. The authors claim that the phase integral method has a certain generality in exhibiting the solution as one of a general class appropriate to problems of this kind; this feature encourages the hope that other problems of the type may be solved by similar methods. The application of this analysis to the wave propagation problem has also afforded a solution to the case not considered in the original problem, but of considerable practical importance, where there is a gradient of refractive index in the atmosphere above the earth.

The paper to which reference is made above presents the detailed analysis involved in this work in a form which exhibits clearly the physical nature of the problem. Formulæ are derived from which the field strength may be obtained for any wavelength, distance from the transmitter and conductivity of the ground over which the waves travel. Furthermore, the increase of field as the receiving post is raised above the earth's surface is obtained, and by using the reciprocal theorem, the analysis applies as well to the case when the receiver is on the ground and the transmitter is elevated. By combining both cases the effect of having both the transmitter and receiver can be calculated.

A very satisfactory feature of this investigation, which will be much appreciated by those engaged in practical radio communication, is that the various formulæ have already been reduced to the compu. tation of numerical values. A paper by T. L. Eckersley (J. Inst. Elec. Eng., 80, 286-304; 1937) gave a complete set of field strength/distance curves for wave-lengths between 2 and $10 \mathrm{~m}$. and for conductivities corresponding to land and sea. Other curves provide the relationship between fieldstrength and height, while a simple means of extending the curves to take account of refraction through the atmosphere is explained for application when the vertical gradient of refractive index of the air is known or can be estimated. While these theoretical results await adequate experimental confirmation, they are already of considerable value as a general guide to the radio engineer; and in this case the graphs referred to above were utilized by the recent International Telecommunications Conference in Cairo in considering a preliminary allocation of bands of ultra-short waves to various classes of radio communication.

$$
\text { R. L. S.-R. }
$$

\section{University Events}

GLasgow.-On September 29, the Gardiner Institute in Medicine, attached to the Western Infirmary, Glasgow, was opened by Lady Gardiner. The Institute is under the direction of the regius professor of medicine in the University, and will be devoted to clinical research. At the opening ceremony, Prof. T. R. Elliott delivered an address in which he stressed the great advantage to be derived from the establishment of such an institute, and emphasized the neces sity of a closer co-operation between the science and practice of medicine.

The following appointments have recently been made in the University : Dr. O. Löwenstein to be lecturer in zoology in succession to Dr. H. B. Cott, newly appointed lecturer in vertebrate zoology, Cambridge; Mr. Vernon D. van Someren to be temporary assistant in zoology in succession to Dr. Margaret W. Jepps, who has been awarded a Leverhulme fellowship for one year. 